\title{
A survey for assessing university performance
}

\author{
Soheila Khosroabadi ${ }^{\mathrm{a}^{*}}$, Baratali Monfaredi raz ${ }^{\mathrm{b}}$ and Hosseinali Bahramzadeh ${ }^{\mathrm{c}}$
}

${ }^{a}$ Master of Educational Administration, Bojnourd, Iran

${ }^{b}$ Ph.D. in Philosophy of Education, Assistant Professor and Scientific Member Azad University of Bojnourd, Bojnourd, Iran ${ }^{c}$ Ph.D. in Public Administration, assistant professor and Scientific Member Azad University of Bojnourd, Bojnourd, Iran

\begin{tabular}{|c|c|}
\hline AR T I C L E I N F O & A B S T R A C T \\
\hline $\begin{array}{l}\text { Article history: } \\
\text { Received May 20, } 2012 \\
\text { Received in Revised form } \\
\text { July, 29, } 2012 \\
\text { Accepted } 15 \text { August } 2012 \\
\text { Available online } \\
28 \text { August } 2012 \\
\text { Keywords: } \\
\text { Performance evaluation } \\
\text { University self assessment } \\
\text { Performance measurement }\end{array}$ & $\begin{array}{l}\text { One of the popular methods to increase the performance of educational services such as public } \\
\text { or private universities is to make performance measurement. The people who work for an } \\
\text { organization are normally considered as the best people to judge about the performance of a } \\
\text { workplace since they know most existing weakness points in their workplace. The proposed } \\
\text { study of this paper looks into a university performance in three inside, process and outside's } \\
\text { perspectives. We design and distribute a questionnaire among } 69 \text { university professors and } 295 \\
\text { students. In this survey, we ask them how they evaluate university in terms of different criteria } \\
\text { such as educational and research facilities, etc. The results of our survey indicate that the } \\
\text { university is not in good condition in terms of research activities but it has maintained good } \\
\text { condition in terms of other perspectives such as educational, infrastructure, etc. }\end{array}$ \\
\hline
\end{tabular}

\section{Introduction}

During the past few decades, there has been tremendous increase on the number of private universities in Iran. The purpose of these schools is to meet educational demands coming from various parts of the country. As a result, we see more competition in various universities and they do their best to increase their capabilities. Universities must comply with rules and regulations and improve their performance by reaching to some standard educational requirements. As a result, it is often possible to make a self-assessment in an attempt to find out more about any existing shortcomings in the system. There are literally different methods for measuring the performance of a university in terms of quantitative and qualitative methods (Kaplan, 1983-4).

Higgins (1989) explained that Performance indicators could be included under three major categories. The first category is associated with internal factors, Internal, e.g. first degree graduation rates, success rates of higher degrees, attraction of research funds. The second category is affiliated with

* Corresponding author. Tel: +989153692760

E-mail addresses: soheilakhosroabadi@yahoo.com (S. Khosroabadi) 
external items, acceptability of graduates in employment, staff publications, patents and the last category is related to operating issues, e.g. unit costs, staff/student ratios, staff workloads. The third category includes a number of traditional problem areas for OR/MS work such as establishing service levels for libraries and computer systems. They used this three-category system to measure the performance of some universities.

Slevin et al. (1991) implemented the application of the Critical Success Factor (CSF) process as a performance measurement and enhancement device in their study. The study used stepwise implementation of the process over a one-year period in a university information systems organization and the procedure described how to refine CSFs using the nominal group technique. They considered some case examples of actual behavior change due to the use of CSFs are given and gave some guidelines for the use of the CSF procedure in other Information Systems (IS) organizational contexts.

Chen (1997) employed data envelopment analysis (DEA) (Charnes et al., 1978, 1994) to measure the relative resource utilization efficiency of 23 university libraries in Taipei City and County. They calculated the overall efficiency score, as well as the technical and scale efficiency scores of each university library. The estimated results demonstrated that 11 university libraries were relatively efficient and nine out of these 11 had a relatively good academic research function. The research also showed that the resource utilization of these university libraries was functioning well and the inefficient libraries could manage their acquisition expenditures and book circulation poorly.

Modell (2003) contrasted goal-directed and institutional approaches to the development of performance measurement (PM) in the Swedish university sector. They adopted a macro perspective, focusing on recent changes in PM associated with governmental control of universities and colleges and combine an extensive review of archival data with interviews. Their empirical analysis helped to reconsider the conceptions of loose coupling as either a "given" feature of institutionalized organizations or an outcome of more pro-active resistance at the micro level prevailing.

Lazzarotti et al. (2011) proposed a formal model for measuring R \& D performance, based on a balanced and synthetic evaluation of quantitative indicators from five various perspectives of performance including financial, customer, innovation and learning, internal business, alliances, and networks. The model was constructed in coherence with the feedbacks coming from the theory of measurement in soft systems, which gives relevant directions for ensuring validity, objectivity and inter-subjectivity of the model.

Wu et al. (2012) performed an investigation to weight the performance evaluation indices for higher education based on the official performance evaluation structure developed by the Taiwan Assessment and Evaluation Association (TWAEA) and to rank 12 private universities listed by the Ministry of Education as a case study. They applied a hybrid multiple-criteria decision-making (MCDM) model to accomplish these objectives, which includes the analytic hierarchy process (AHP) and VIKOR methods (Fontela \& Gabus, 1976). They also compared the official rankings of the 12 private universities with their ranking of the same universities and tried to help universities optimize their performances with efficiency.

University physical conditions such as air-condition plays essential role on increasing university performance and there are some studies associated with the effect of physical condition on student performance. Lee et al. (2012), for instance, examined classroom learning performance and indoor environmental quality (IEQ) and reported that student overall IEQ votes associated with the environmental parameters. They also reported that each of environmental parameters had similar impact on learning performance and an increase in the number of complaints decreased student learning performance. 
Measuring the performance of a university or other business units does not solely depend on financial figures only and profitability could come through other important issues such as internal processes, customer, etc. (Kaplan \& Norton, 1992, 1996, 2001). Balanced score card is another important performance measurement technique, which was originally introduced by Kaplan and Norton.

In this paper, we present an empirical study to measure the performance of one of private universities located in city of Bojnord, Iran.

\section{The proposed study}

The proposed study of this paper uses three factors of internal, external and operating issues associated with the performance of the university. The study considers the following questions in each part of the survey,

\subsection{Internal objectives}

Internal objectives includes eight questions, which are as follows,

1. Having updated educational and training programs,

2. Having good infrastructure to absorb more students based on local region's requirements,

3. Having an appropriate educational and administration and recreational facilities based on students' needs,

4. Having upgraded human resources in terms of regular staff and university professors,

5. Development cultural and educational based on the present culture of society,

6. Having appropriate workshops and encouraging university professors to participate,

7. Assuming responsibility to meet students' needs.

\subsection{Process objectives}

The second item is associated with the process objectives and it includes the following items,

1. Increase use of information technology and recent advances of technological achievements for improving learning skills,

2. Facilitating research objectives along with teaching tasks,

3. Increase efforts on improving students' performance by monitoring their performances,

4. Improving university professors' performances by setting appropriate targets,

5. Creating opportunities to increase group team work and optimum use of existing capacities,

6. Educating dedicated and creative students who could contribute to country's 20-year objectives,

7. Educating skilled people who are either hired by industry or they could create jobs and opportunities,

8. Acting as leadership position on creating knowledge,

9. Developing good organizational culture to increase the quality of educational services. 


\subsection{External objectives}

1. Preparing good environment to help students continue their educations,

2. Providing good consultation for domestic industry,

3. Training highly qualified people for industry,

4. Training highly qualified people for doing research activities,

5. Training highly qualified students who could contribute to society.

We use the following formula to calculate the minimum number of sample size,

$n=\frac{N \times z_{\alpha / 2}^{2} \times p \times q}{\varepsilon^{2} \times(N-1)+z_{\alpha / 2}^{2} \times p \times q}$,

where $N$ is the population size, $p=1-q$ represents the yes/no categories, $z_{\alpha / 2}$ is CDF of normal distribution and finally $\varepsilon$ is the error term. Since we have 99 university professors therefore $p=0.5, z_{\alpha / 2}=1.96$ and $N=99$ and the number of sample size is calculated as $n=69$. Similarly we calculated the number of sample size from 6103 students who attend this school as 295. All questions were designed in Likert scale (Likert, 1932) from one to five where one represents the lowest impact and five represents the highest impact. In this study, the responses are averaged using weighted average method and any result less than 2.33 was considered as undesirable, the range of 2.34 to 3.66 was considered desirable and any number greater than 3.66 was considered as highly desirable. In this survey, we ask them how they evaluate university in terms of different criteria such as educational and research facilities, etc. The questions are categorized in five groups including educational, research, infrastructure, process and evaluation. Cronbach alpha (Cronbach, 1952) for questionnaires gathered from university and students were calculated as 0.89 and 0.93 , respectively, which are well above the minimum recommended level of 0.7. Therefore, we can conclude that the questionnaire maintains a good reliability and the results could be interpreted for the study.

\section{The results}

As we have explained earlier, the questionnaires are distributed between two groups of university professors and students. Next, we present the survey results gathered from university professors and Table 1 shows details of our survey.

\section{Table 1}

The results of the survey among university professors

\begin{tabular}{lccc}
\hline Category & Average & Number & Result \\
\hline Educational affairs & 3.57 & 69 & Desired \\
Research affairs & 2.82 & 69 & Desired \\
Infrastructure affairs & 3.19 & 69 & Desired \\
Process & 3.52 & 69 & Desired \\
Evaluation & 3.70 & 69 & Highly Desired \\
\hline
\end{tabular}

As we can observe from the results of Table 1, most university professors believe that the university is in good position in terms of educational, research, infrastructure and process. They also believe the university is in better position in terms of evaluation compared with other items. It is always a good idea to hear the voice of customers when we make performance measurement. Students are primary customers of such units, and Table 2 shows details of our findings. 
Table 2

The results of the survey among university students

\begin{tabular}{lccc}
\hline Category & Average & Number & Result \\
\hline Educational affairs & 3.03 & 295 & Desired \\
Research affairs & 2.17 & 295 & Undesired \\
Infrastructure affairs & 2.68 & 295 & Desired \\
Process & 3.09 & 295 & Desired \\
Evaluation and assessment & 2.78 & 295 & Desired \\
\hline
\end{tabular}

The results of Table 2 show that most students believe that research activities are poorly accomplished at this university and students and university professors are not able to do research at this school well. Overall, students seem to be more cautious about university's capabilities compared with what university professors believed and this could send a signal to university officials to look for possible actions to increase their performance.

\section{Conclusion}

In this paper, we have presented an empirical study to measure the performance of a privately held university located in one of eastern Iranian cities called Bojnord. We have designed and distributed a questionnaire among samples from students and university professors at this school in five different perspectives including educational, research, infrastructure, process and evaluation and assessment figures. The results of our survey have indicated that the university is not in good condition in terms of research activities but it has maintained good condition in terms of other perspectives.

\section{Acknowledgment}

The authors would like to thank the officials of Islamic Azad University of Bojnord for providing support for accomplishment of this survey. We are also delighted for constructive comments on earlier version of this paper given by anonymous referees.

\section{References}

Charnes, A., Cooper, W. W., \& Rhodes, E. (1978). Measuring the efficiency of decision making units. European Journal of the Operational Research, 2, 429-44.

Charnes, A., Cooper, W. W., Lewin, A., \& Seiford, L. M. (1994). Data envelopment analysis: theory, methodology and applications. Massachusetts: Kluwer Academic Publishers.

Chen, T.Y. (1997). A measurement of the resource utilization efficiency of university libraries. International Journal of Production Economics, 53(1), 71-80.

Cronbach, L. J. (1951). Coefficient alpha and the internal structure of tests. Psychometrika, 16(3), 297-334.

Fontela, E., \& Gabus, A. (1976). The DEMATEL observer. DEMATEL 1976 Report. Switzerland, Geneva: Battelle Geneva Research Center.

Higgins, J.C. (1989). Performance measurement in universities. European Journal of Operational Research, 38(3), 358-368.

Kaplan, R. (1983). Measuring manufacturing performance: A new challenge for management accounting research. The Accounting Review, 686-705.

Kaplan, R. (1984). The evolution of management accounting. The Accounting Review LIX, 3, 390418.

Kaplan, R. S., \& Norton, D. P. (1992). The balanced scorecard-measures that drive performance. Harvard Business Review.

Kaplan, R. S., \& Norton, D. P. (1996). Translating strategy into action: The balanced scorecard. Boston: Harvard Business School Press. 
Kaplan, R. S., \& Norton, D. P. (2001). The strategy-focused organization: How balanced scorecard companies thrive in the new business environment. Boston: Harvard Business School Press.

Lazzarotti, V., Manzini, R., \& Mari, L. (2011). A model for R\&D performance measurement. International Journal of Production Economics, 134(1), 212-223.

Lee, M.C., Mui, K.W., Wong, L.T., Chan, W.Y., Lee, E.W.M., \& Cheung, C.T. (2012). Student learning performance and indoor environmental quality (IEQ) in air-conditioned university teaching rooms. Building and Environment, 49, 238-244.

Likert, R. (1932). A Technique for the Measurement of Attitudes. Archives of Psychology, 140, 1-55.

Modell, S. (2003). Goals versus institutions: the development of performance measurement in the Swedish university sector. Management Accounting Research, 14(4), 333-359.

Slevin, D.P., Stieman, P.A., \& Boone, L.W. (1991). Critical success factor analysis for information systems performance measurement and enhancement: A case study in the university environment. Information \& Management, 21(3), 161-174.

Wu, H.Y., Chen, J.K., Chen, I.S., \& Zhuo, H.H. (2012). Ranking universities based on performance evaluation by a hybrid MCDM model. Measurement, 45(5), 856-880 